\title{
Region Based Segmentation using TCRM
}

\author{
M. Umaselvi, E. Menaka
}

\begin{abstract}
Water Resource is one of the essential supplies of the globe environment which needs to be regularly observed. There is rising need and necessitate in research of water region detection due to the unpredicted natural calamity that guide to financial, environment and individual sufferers. Assessment of water region (WR) and study on its characteristic is very fundamental step for many scheduling, particularly for country like India which made frequent changes on WR. Basically, recognize the WR from Remote sensing images is one of the impressive steps of water possessions organization for a country where it has been used superior than decades for WR detection. Techniques of WR extraction can be examine into three groups: Texture Conditional Rotation Mean (TCRM), feature extraction using TCRM algorithms, Region based segmentation. These methods, though, are of mathematical and statistical approach and little of them look at important uniqueness of multispectral image which is found on land object radiance absorption performance in every sensing spectral bands. In visible and infrared bands, the WR spectral absorption characteristics differ very much from the other earth substance. There are different data bases for the study area which consists of different form and exposure. Results show that TCRM presents adequate well detection for WR as speedy and receiving high accuracy with the suitable threshold rate.

Keywords : Remote sensing images, Assessment of water region, Feature extraction.
\end{abstract}

\section{INTRODUCTION}

The assessment of water resources data from remote sensing by several researchers in various fields such as hydrology, oceanography, and natural science found that the environmental inaccessibility of the isolated region which causes plentiful challenge in their mapping progress. It could be hard to find because of its usual geographic arrangement. Hence, the complete preparation, revelation and analysis essential for functioning in such areas for development of the nation. Despite the fact that, most of the man made water storage dam and reservoirs are situated in mountainous zones where its topographic shadows show analogous in optical data, which is the origin for misunderstanding in the recognition and description of water. It is the most important challenge in satellite image processing.

The methods that only exploit the spectral variables

Revised Manuscript Received on April 02, 2020.

* Correspondence Author

Dr. M. Umaselvi, Associate Professor, P. A. College of Engineering and Technology, Palladam Road, Pollachi, Coimbatore - 642002, India. umaselvisadeeskumar@gmail.com

Dr. E. Menaka*, Associate Professor, Vivekanandha College of Engineering for Women, Elayampalayam, Namakkal, Tamilnadu 642247, India. menakaparthi80@gmail.com

(C) The Authors. Published by Blue Eyes Intelligence Engineering and Sciences Publication (BEIESP). This is an open access article under the CC BY-NC-ND license (http://creativecommons.org/licenses/by-nc-nd/4.0/) derived from image pixels may be used to the most well-liked system of LULC for region, urban area, and vegetation. The recognition of very important and unimportant features is a significant element in image processing. The intensity property implemented in the segmentation process is not adequate to differentiate the water object in remotely sensed images. Accordingly, it needs derivative information of WR and which is a demanding assignment for regular clustering since its difficult textures and their properties. Subsequently study activities, away from the spectral, spatial information or the association among adjacent pixels were discover through OBIA (Csathó et al 1999) which usually get better accuracy with respect to the pixel-based approach (Myint et al 2011, Menaka \& Suresh Kumar 2014, 2015) also it is preferable since WR characterize in its proper spatial landscape model as an alternative to a squared classified pixel (Blaschke \& Strobl 2001). Texture features commonly used in OBIA and have been exposed to progress discrimination and segmentation accuracy (Arcidiacono et al 2012) in various land cover categories.

Some of methods execute texture analysis directly on the gray levels such as GLCM (Haralick et al 1973), autocorrelation function analysis (Lin et al 1997), Generalized Co-occurrence Matrices (GCM) (Hauta et al 1996), second order spatial averages (Gagalowicz 1988), and two-dimensional filtering in the spatial and frequency domain (Coggins \& Jain 1985). The approaches rely on color image applied a single spectral band (Pesaresi \& Gerhardinger 2011) that describe the spatial changeability within the bands to generate texture images. Wentz et al (2006) described that instead of choosing a single, a multiband texture could be derived from all suitable spectral bands.

Fisher et al. (2016) applied multiple water indices using multi-temporal Landsat (TM, ETM and OLI) satellite images for Automated Water Extraction Index with shadow (AWEIsh) and by no shadow (AWEInsh), Tasseled Cap Wetnes (TCWCrist) NDWI and Water Index (WI2015) and examined performance and correctness outcomes of said indices on clean and varied water pixels. Although the complication neural networks beneath the deep learning structure has been broadly used to find the objective in satellite images by categorized training sample (Isikdogan et al., 2017), limited researches have stated the demonstration of deep learning to satellite data at great scale. Wei Jiang et al., (2018) proposed the Multi-Layer Perceptron (MLP) method beneath deep learning basis to detect WR and classify image using Maximum Likelihood (ML) and water index using Landsat 8. Acharya et al. (2017) applied four different indices to Landsat 8 OLI satellite images of to Phewa Lake's.

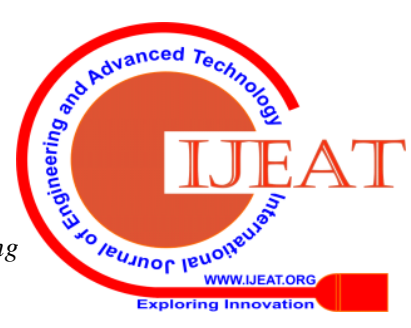


The classification with the combination of these indices, including Normalized Difference Water Index (NDWI), Modified Normalized Difference Water Index (MNDWI), Water Ratio Index (WRI), and Normalized Difference Vegetation Index (NDVI) shows better results than those of spectral bands. Therefore, this work make use of modified mean and variance algorithm as a corrective procedure to detect the dam and reservoir WR multispectral image and it is illustrate in the subsequent divisions.

\section{STUDY AREA}

The study area is Mettur dam, which is one of the largest water storage dam constructed across the Kaveri River in Salem District, Tamil Nadu, is locating in Southern India. The area, enclosed with $76^{\circ} 38^{\prime} 46.86 " \mathrm{E}$ longitude, $10^{\circ} 07^{\prime} 20.86^{\prime \prime N}$ latitude, path 144, row 53 (data acquired on 2016/03/20) where image covers 1300 sq. Meters is showing in Figure 1. The water infinite by part of the Salem, Namakkal, Karur, Trichy, and Thanjavur are giving the asset to the Tamilnadu. The length is 1,700 meters $(5,600 \mathrm{ft})$, the level of the dam is $120 \mathrm{ft}$ (37 meters), and the maximum capacity is 93.47 tmc. Due to lack of rainfall, the dam receives low water, and nearly goes dry during summer season (April-June). Most of the farmers and publics life is depending upon this dam water. The hotness range differ in summer from $29^{\circ} \mathrm{C}\left(84^{\circ} \mathrm{F}\right)$ to $37^{\circ} \mathrm{C}\left(99^{\circ} \mathrm{F}\right)$ and in winter $20^{\circ}$ $\mathrm{C}\left(68^{\circ} \mathrm{F}\right)$ to $26^{\circ} \mathrm{C}\left(79^{\circ} \mathrm{F}\right)$ and an yearly usual rainfall of 812 $\mathrm{mm}$.

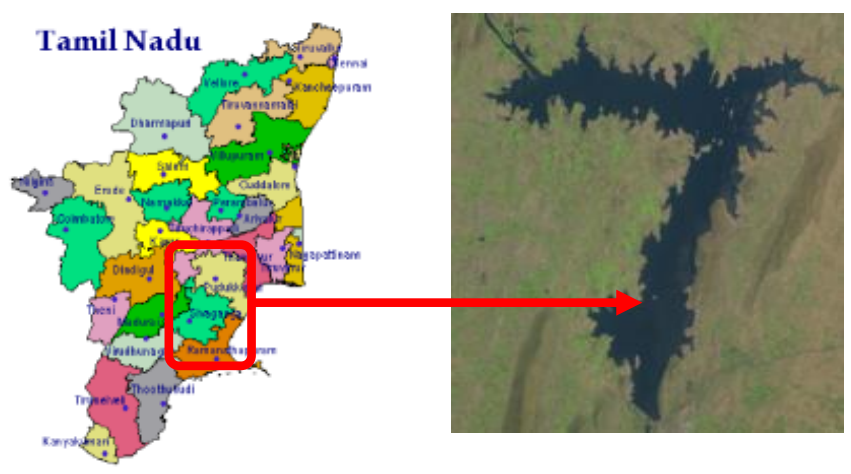

Figure 1 Study Area of Mettur Dam [Source: www.mapsofindia.com]

\section{SIGNIFICANCE OF TEXTURE}

The texture extraction plays an essential part in numerous techniques to detect water zones based on spatial distinction of intensity values (Akay \& Aksoy2008) where it permitted the image structure mining which is not noticeable by others (Breckle \& Wucherer 2006). It evaluate the variability in locale structure (Wood et al 2012) of color values between adjacent pixels in a digital image. Also it enumerates illustration characteristics of the image such as smoothness, roughness, symmetry, directionality and relationship between them. Depends on the image source, it can be considered on single or multiple bands, with all dissimilar information regarding the spatial associations of neighborhood pixels. Also, the Haralick measures on the color images provide the improved accuracy for segmentation (Menaka \& Suresh Kumar 2015).

\section{RULE - BASED SEGMENTATION}

The water pixels in the RS images are homogenous (uniform and flat) even though some local variability is available in brightness. The irregular water and thin water gives specular reflection and bottom reflection. Variability of atmospheric radiance, sensor gain variation and mixed pixels are the factors which affect and vary the light intensity from water (Wilson 1997). However, Haralick et al (1973) proposed texture for land-use segmentation including water, farm land, soil and urban area. Jupp et al (1985) used Root Mean Square (RMS), calculated in 3x3 windows between central and its neighboring pixels in WR given in Equation (1).

$$
p(i, j)=\sum_{i=1}^{N_{g}} \sum_{j=1}^{N_{g}}(i-\mu)^{2} p(i, j)
$$

Where

$\mathrm{p}(\mathrm{i}, \mathrm{j})$-> spatial dependence matrix of $(\mathrm{i}, \mathrm{j})^{\text {th }}$ entry

$\mu->$ the mean value of the image $p$

$\mathrm{Ng}->$ quantized distinct gray levels

Similarly variance filter (VF) defined as "local amplitude can be measured using variance" which proposed by Jain (1989) to measure uniformity of water where it calculates variance of the neighboring pixels in the $\mathrm{n}$ group which replaces the central pixel (Wilson 1997) is given in Equation 2.

$$
S_{x}=\frac{1}{N-1} \sum_{i=1}^{n_{1}}\left(x_{i}-\bar{x}\right)^{2}
$$

where

$\mathrm{N}->$ the number of pixels in the set

$\mathrm{x}_{\mathrm{i}}->$ the value of pixel $\mathrm{i}$

$\bar{x}$->the mean of neighboring pixel values

Some of the data values are affected by neighbor goods when applying VF due to the causes of external factors. Thus it leaves a few WR as unclassified which is very much necessary to segment its boundaries between vegetation, rock, sand, and soil. So, the new modified feature extraction algorithm proposed in the next section.

\section{TEXTURE CONDITIONAL ROTATION VARIANCE (TCRV)}

The proposed TCRV algorithm is used for extraction which eliminates the limitations of VF. It is developed based on Conditional Rotation and Variance where the condition is set by the manual input which selects the pixels to calculate the variance value of the image in $3 \times 3$ and $5 \times 5$ windows. The center pixel called as Region of Interest (RoI) which set as an origin point to rotate the window shown in Figure 2.

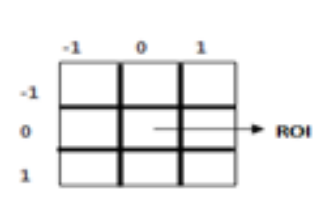

(a) $3 \times 3$ Matrix

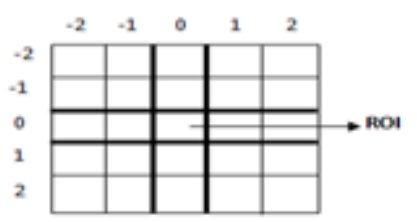

(b) $5 x 5$ matrix
Figure 2 TCR Pixel Positions

Published By:

Blue Eyes Intelligence Engineering \& Sciences Publication

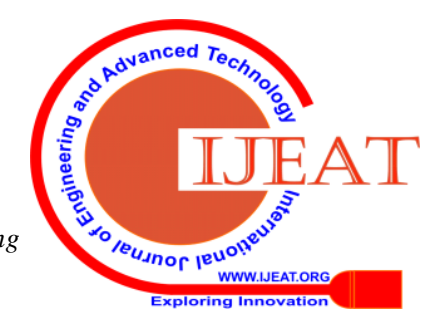


The RoI is replaced by the variance value of 8 pixels and the resultant value produces the textured image using the Equation 3 \& 4.

$$
\begin{aligned}
& I(i, j)=\frac{1}{8} \sum_{i=-1}^{1} \sum_{j=-1}^{1}\left(I(i, j) \quad \begin{array}{l}
\mathrm{i}=0, \mathrm{j}<0: \mathrm{L} \\
\mathrm{i}=0, \mathrm{j}>0: \mathrm{R} \\
\mathrm{i}<0, \mathrm{j}=0: \mathrm{U}
\end{array}\right. \\
& \text { where } \quad c \mu=\frac{1}{8} \sum_{i=-1}^{1} \sum_{j=-1} I(i, j) \quad \begin{array}{l}
\mathrm{i}<0, \mathrm{i}<\mathrm{j}>0: \text { UR } \\
\mathrm{i}>0, \mathrm{j}<0: \mathrm{L}_{\mathrm{O}} \mathrm{L} \\
\mathrm{i}>0, \mathrm{j}>0: \mathrm{L}_{\mathrm{O}} \mathrm{R}
\end{array}
\end{aligned}
$$

$$
\begin{gathered}
c \mu= \\
(\mathrm{I}(\mathrm{i}-1, \mathrm{j}-1)+\mathrm{I}(\mathrm{i}-1, \mathrm{j})+\mathrm{I}(\mathrm{i}-1, \mathrm{j}+1)+\mathrm{I}(\mathrm{i}, \mathrm{j}-1)+\mathrm{I}(\mathrm{i}, \mathrm{j}+1)+
\end{gathered}
$$$$
\mathrm{I}(\mathrm{i}+1, \mathrm{j}-1)+\mathrm{I}(\mathrm{i}+1, \mathrm{y})+\mathrm{I}(\mathrm{i}+1, \mathrm{j}+1)) / 8
$$

where

$$
\mathrm{I}(\mathrm{i}, \mathrm{j}) \text {-> image pixel }
$$

$c \mu->$ conditional mean value

It is a three phase process. First, conditional mean value calculated using 8 pixels of RoI which are selected by applying TCR. Secondly the mean is subtracted from each surrounding values and summed up its variance called Conditional Rotation Variance (CRV). Finally, the RoI replaced by CRV value.

\section{TEXTURE CONDITIONAL ROTATION MEAN (TCRM)}

It is developed based on the conditional rotation and mean where the condition is set by manual which selects the pixels to calculate the mean value of the image. The dimension of the sliding window takes account of the sufficient and essential for WR which manipulates the accuracy. Thus, the option of sub-window is a vital step with different resolutions, texture parameters and its expressions. Therefore, there is a need to select suitable size. In this proposed method, two kinds of sliding windows $3 \times 3$ and $5 \times 5$ applied for feature extraction. The derivative gives eight new algorithms which are directional oriented such as Diagonal (D), Horizontal (Left - L, Right - R), Vertical (Upper - U, Lower - Lo) and its combinations of 3x3 which shows in Equation 5 to 11 .

DIA

$$
I(i, j)=\frac{1}{4} \sum_{i=-1}^{1} \sum_{j=-1} I(i, j) \quad \begin{aligned}
& \mathrm{i}<0, \mathrm{j}>0: \mathrm{UR} \\
& \mathrm{i}>0, \mathrm{j}<0: \mathrm{L}_{0} \mathrm{~L} \\
& \mathrm{i}>0, \mathrm{j}>0: \mathrm{L}_{0} \mathrm{R}
\end{aligned}
$$

LR

$$
I(i, j)=\frac{1}{2} \sum_{j=-1}^{1} I(i, j) \quad \begin{aligned}
& \mathrm{i}=0, \mathrm{j}<0: \mathrm{L} \\
& \mathrm{i}=0, \mathrm{j}>0: \mathrm{R}
\end{aligned}
$$

\section{LRD}

$$
I(i, j)=\frac{1}{6} \sum_{i=-1} \sum_{j=-1}^{1} I(i, j) \quad \begin{aligned}
& \mathrm{i}=0, \mathrm{j}<0: \mathrm{i}<0, \mathrm{j}>0: \mathrm{R} \\
& \mathrm{i}<0, \mathrm{j}>0: \mathrm{UR} \\
& \mathrm{i}>0, \mathrm{j}<0: \mathrm{L}_{0} \mathrm{~L} \\
& \mathrm{i}>0, \mathrm{j}>0: \mathrm{L}_{0} \mathrm{R}
\end{aligned}
$$

$\mathrm{UL}_{\mathrm{o}}$

$$
I(i, j)=\frac{1}{2} \sum_{i=-1}^{1} I(i, j) \quad \begin{aligned}
& \mathrm{i}<0, \mathrm{j}=0: \mathrm{U} \\
& \mathrm{i}>0, \mathrm{j}=0: \mathrm{L}_{\mathrm{o}}
\end{aligned}
$$

$$
\begin{aligned}
& \mathrm{UL}_{0} \mathrm{D} \\
& I(i, j)=\frac{1}{6} \sum_{i=-1}^{1} \sum_{j=-1}^{1} I(i, j)
\end{aligned}
$$

$$
\begin{aligned}
& \mathrm{i}<0, \mathrm{j}=0: \mathrm{U} \\
& \mathrm{i}>0, \mathrm{j}=0: \mathrm{L}_{\mathrm{o}} \\
& \mathrm{i}<0, \mathrm{j}<0: \mathrm{UL} \\
& \mathrm{i}<0, \mathrm{j}>0: \mathrm{UR} \\
& \mathrm{i}>0, \mathrm{j}<0: \mathrm{L}_{\mathrm{o}} \mathrm{L} \\
& \mathrm{i}>0, \mathrm{j}>0: \mathrm{L}_{\mathrm{O}} \mathrm{R}
\end{aligned}
$$

$$
\begin{aligned}
& \mathrm{LRUL}_{\mathrm{o}} \\
& \qquad I(i, j)=\frac{1}{4} \sum_{i=-1}^{1} I(i, j)
\end{aligned}
$$

$$
\begin{aligned}
& \mathrm{i}=0, \mathrm{j}<0: \mathrm{L} \\
& \mathrm{i}=0, \mathrm{j}>0: \mathrm{R} \\
& \mathrm{i}<0, \mathrm{j}=0: \mathrm{U} \\
& \mathrm{i}>0, \mathrm{j}=0: \mathrm{L}_{0}
\end{aligned}
$$

$$
\begin{aligned}
& \mathrm{LRUL}_{0} \mathrm{D} \\
& I(i, j)=\frac{1}{8} \sum_{i=-1}^{1} \sum_{j=-1}^{1} I(i, j)
\end{aligned}
$$

$\mathrm{i}=0, \mathrm{j}<0: \mathrm{L}$

$\mathrm{i}=0, \mathrm{j}>0: \mathrm{R}$

$\mathrm{i}<0, \mathrm{j}=0: \mathrm{U}$

$\mathrm{i}>0, \mathrm{j}=0: \mathrm{L}_{\mathrm{o}}$

$\mathrm{i}<0, \mathrm{j}<0: \mathrm{UL}$

$\mathrm{i}<0, \mathrm{j}>0$ : UR

$\mathrm{i}>0, \mathrm{j}<0: \mathrm{L}_{0} \mathrm{~L}$

$\mathrm{i}>0, \mathrm{j}>0: \mathrm{L}_{0} \mathrm{R}$

eq. 9

eq. 10

eq. 11

Where $\quad I(i, j)$ represents image pixel

DIA-Diagonal, LR-Left Right, LRD-Left Right Diagonal, $\mathrm{UL}_{0}$-Upper Lower, $\mathrm{UL}_{0} \mathrm{D}$-Upper Lower Diagonal, LRUL $_{0}$ - Left Right Upper Lower, LRUL $_{0}$ D-Lower Right Upper Lower Diagonal.

The TCRM using D considered 4 pixels of RoI. The LR and UL processed with 2 pixels each and 6 pixels taken for the combination of D with UL and LR. The mean calculated and it replaces the RoI according to the derivatives. TCRM using LRULD 5x5 window pixel positions are shown in Equation 12 \& 13 .

$$
I(i, j)=\frac{1}{24} \sum_{i=-2}^{2} \sum_{j=-2}^{2} I(i, j)
$$

eq. 12

$\mathrm{I}(\mathrm{x}, \mathrm{y})=$

$(\mathrm{I}(\mathrm{x}-2, \mathrm{y}-2)+\mathrm{I}(\mathrm{x}-2, \mathrm{y}-1)+\mathrm{I}(\mathrm{x}-2, \mathrm{y})+\mathrm{I}(\mathrm{x}-2, \mathrm{y}+1)+$

$\mathrm{I}(\mathrm{x}-2, \mathrm{y}+2)+\mathrm{I}(\mathrm{x}-1, \mathrm{y}-2)+\mathrm{I}(\mathrm{x}-1, \mathrm{y}-1)$

$+\mathrm{I}(\mathrm{x}-1, \mathrm{y})+\mathrm{I}(\mathrm{x}-1, \mathrm{y}+1)+$

$\mathrm{I}(\mathrm{x}-1, \mathrm{y}+2)+\mathrm{I}(\mathrm{x}, \mathrm{y}-2)+\mathrm{I}(\mathrm{x}, \mathrm{y}-1)+\mathrm{I}(\mathrm{x}, \mathrm{y}+1)+\mathrm{I}(\mathrm{x}, \mathrm{y}+2$

)+

$\mathrm{I}(\mathrm{x}+1, \mathrm{y}-2)+\mathrm{I}(\mathrm{x}+1, \mathrm{y}-1)+\mathrm{I}(\mathrm{x}+1, \mathrm{y})+\mathrm{I}(\mathrm{x}+1, \mathrm{y}+1)+$

$\mathrm{I}(\mathrm{x}+1, \mathrm{y}+2)+\mathrm{I}(\mathrm{x}+2, \mathrm{y}-2)+\mathrm{I}(\mathrm{x}+2, \mathrm{y}-1)+\mathrm{I}(\mathrm{x}+2, \mathrm{y})+$

$\mathrm{I}(\mathrm{x}+2, \mathrm{y}+1)+\mathrm{I}(\mathrm{x}+2, \mathrm{y}+2)) / 24$

where $\mathrm{I}(\mathrm{x}, \mathrm{y})$-> image pixel

$\mathrm{x}, \mathrm{y}->$ row and column values of I.

eq. 6

\section{RESULT AND DISCUSSION}

This study presents a root for prudent water organization of large basins. Civilization around the world has long fought with the planning and management of WR with growing populations, resource uses, ecosystem degradation and climate change where the decisions can reduce the impacts of geologic scale. Extraction of WR from SAR images using thresholding, noise removal, SAR amplitude and terrain information produces the overall accuracy of $96.48 \%$ after differentiating the misclassified segments, while amplitude eq. 8 detail alone produces only 83.67\%.

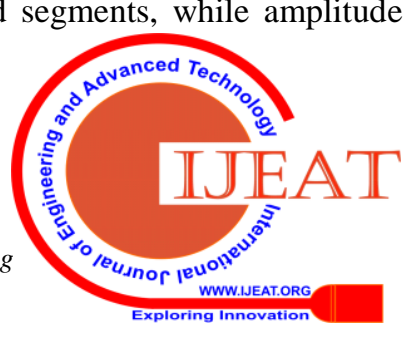


Hence, the proposed algorithm provides the right result on different Landsat 8 images of dam and reservoirs.The occurrence of WR determined by TCR which explained in the sub section 5 . It produces coarse image and applied multiresolution segmentation with varying threshold to splits the water area from various objects such as forest, land, rock and sandy regions for precise results. The following Equations 14 \& 15is used to test the accuracy and fault tolerance:

$$
\begin{aligned}
& \text { Segmentation Accuracy } \\
& =\frac{\text { Segmented water pixels by the algorithm }}{\text { Sample Image water pixels }} \\
& \text { Fault Tolerance } \\
& =\frac{\text { Missed water pixels by the algorithm }}{\text { Sample Image water pixels }}
\end{aligned}
$$

The results of WR using 11 algorithms with a threshold of 225 for Mettur dam is shown in Figure 3 and Table 1. The sample outputs ant its accuracies are shown in Figure 4 and Table 2-3. The yellow boundary is the objective WR which obtained by proposed methods and green is the other land uses. It acquires good results except in areas near to the dense forest and wetland where pixels could not well segregated. The notable one is that the small WR covered by hill or rock and small land covered by WR also well processed.

HKM, DIA and LRULD 5X5produces over segmentation i.e., the mountain shadow and dense forest boundaries are recognized as WR due to its backscattered values. Also, HKM forms many inner clusters within WR.ULD is not entirely cover the overall WR and it splits WR into groups which includes wetland and other Land objects. LRUL performs same as LR which ignores the slant WR in the corner region. LRULD using $5 \times 5$ removes the non-water area entirely which covers only WR where it includes non WR as water. HKV creates many groups like ULD and left the few WR as non water. LRULD $3 \times 3$ obtained the exact WR and achieved high accuracy. To analyze this work, 100 subsets created from 7 different locations in India where the LRULD $3 \times 3$ reached overall accuracy of 98.96\% with fault tolerance of $1.03 \%$ is shown in Table 1 . The running time also considerably less compared to other algorithms.

\section{CONCLUSION}

The work carried out in this study presents a new technique for detecting and extracting the specific WR which observe the status of water resources fast and timely which affords enormous instant impact for protecting the surroundings and attains sustainable growth. A meticulous examination has been specified since its accurate surveying is extremely significant for Central Water Commission where the methodologies found valuable to take precautionary actions against water scarcity and flood which facilitates to improve the correctness in the RS lake, river and reservoir. TCRM gives enough fine position for extracting WR as fast and getting high precision with the appropriate threshold value. Also, this proposed work may be integrated with other algorithms such as TCR Haar Wavelet and Hard clustering.

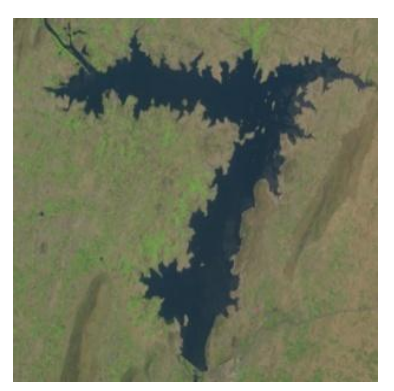

a)

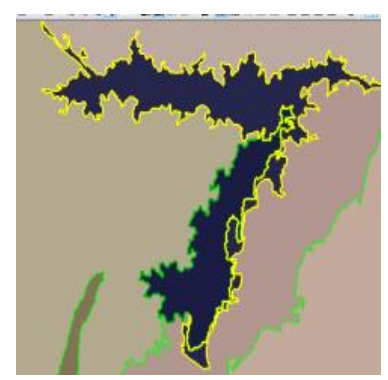

b)

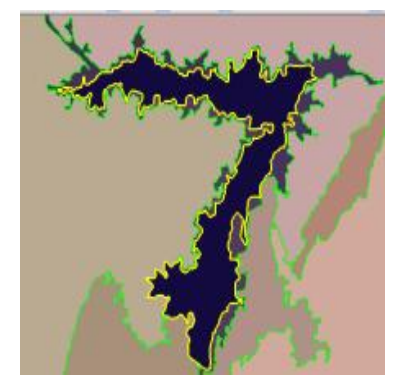

c)

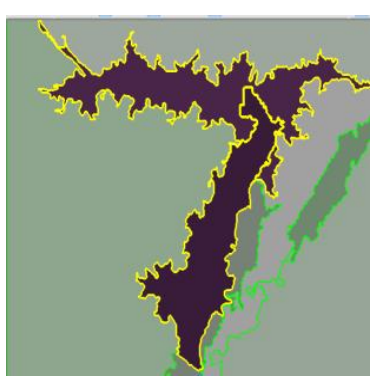

d)

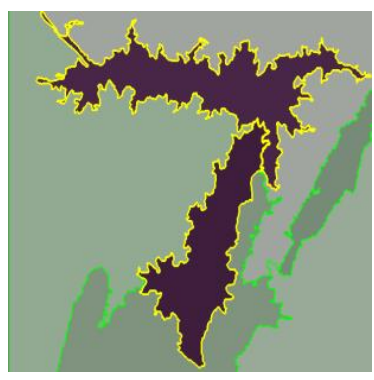

e)

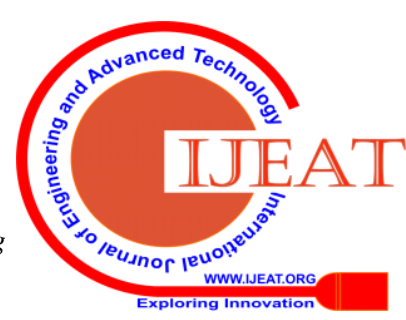




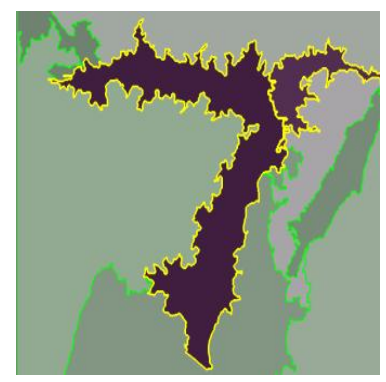

f)

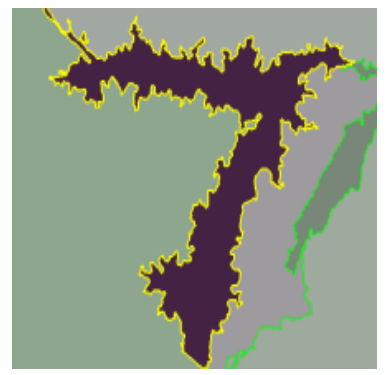

j)

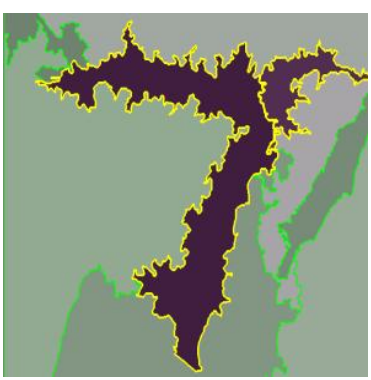

g)

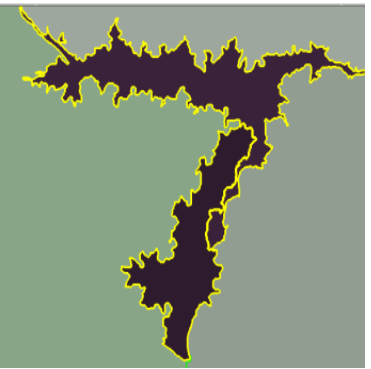

k)

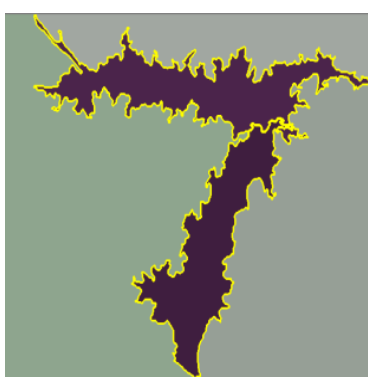

h)

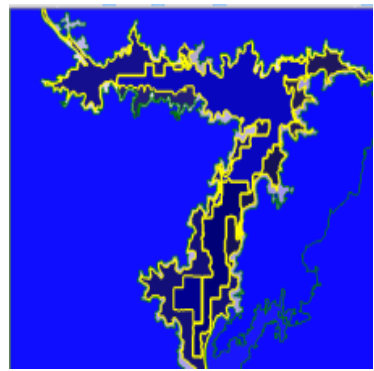

1)

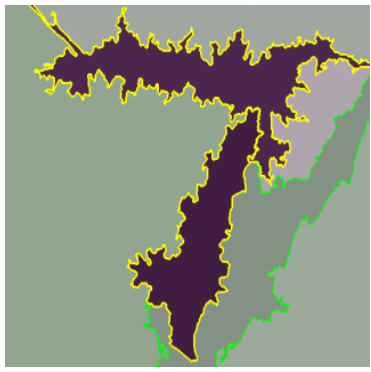

i)

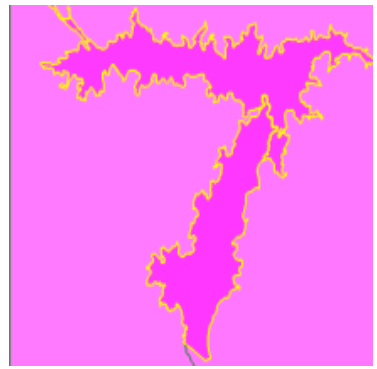

m)

Figure 3 TCR Resultant Images of Mettur Dam, a) Original Image, b) Multiresolution Segmentation Image, c) HKM image, d) DIA image, e) LR image, f) LRD image, g) UL image, h) ULD image,i)LRUL image, j)LRULD 3x3 image, k)LRULD $5 \times 5$ image, l)HKV image, m)TCRV image

Table 1 Accuracy Analysis of Mettur Dam

\begin{tabular}{|l|c|c|c|}
\hline \multicolumn{1}{|c|}{ Algorithms } & $\begin{array}{c}\text { Accuracy } \\
\text { \% }\end{array}$ & $\begin{array}{c}\text { FT } \\
\text { \% }\end{array}$ & $\begin{array}{c}\text { RT } \\
\text { in Sec. }\end{array}$ \\
\hline HKM & $104.2574^{*}$ & -4.25744 & 95.47682 \\
\hline DIA & 98.30153 & 1.698466 & 42.31791 \\
\hline LR & 93.636 & 6.364 & 26.06791 \\
\hline LRD & 94.0876 & 5.912402 & 35.84285 \\
\hline UL $_{0}$ & 97.27182 & 2.728181 & 30.52501 \\
\hline UL $_{0}$ D & 97.59572 & 2.40428 & 56.37228 \\
\hline LRUL $_{0}$ & 98.92516 & 1.074836 & 66.31515 \\
\hline LRUL $_{0}$ D 3X3 & 99.90723 & 0.092769 & 10.00709 \\
\hline LRUL $_{0}$ D 5X5 & 93.53487 & 6.465128 & 74.96019 \\
\hline HKV & 87.73688 & 12.26312 & 96.0465 \\
\hline TCRV & 96.79 & 3.210004 & 87.6861 \\
\hline
\end{tabular}

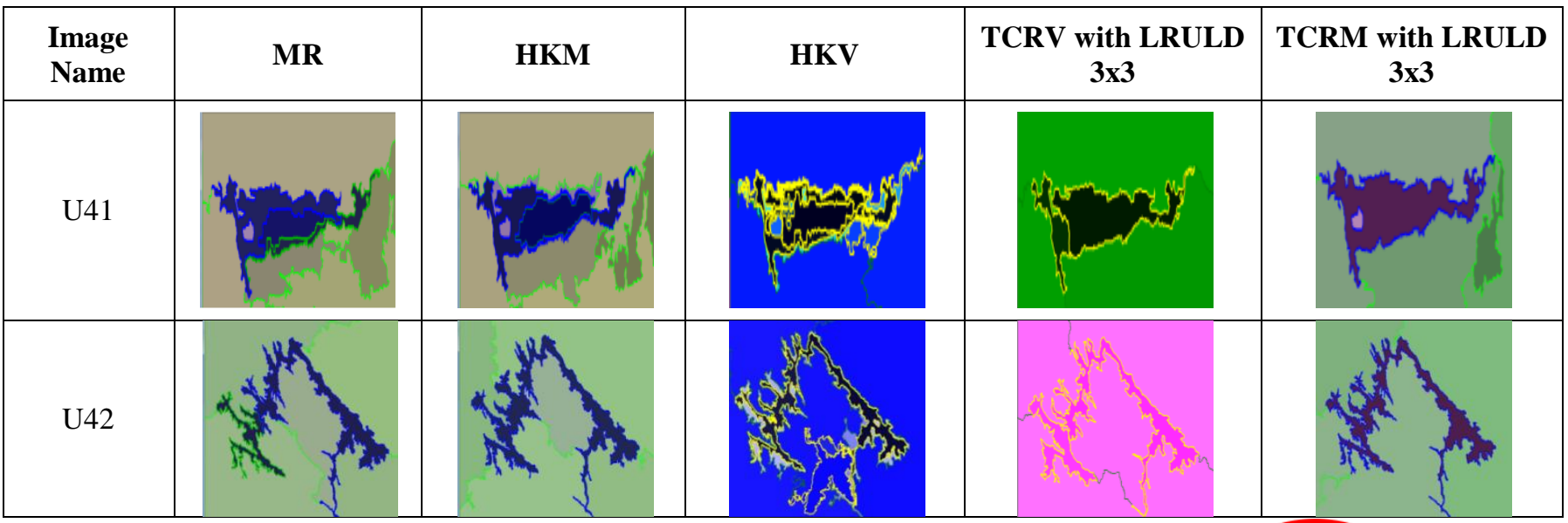




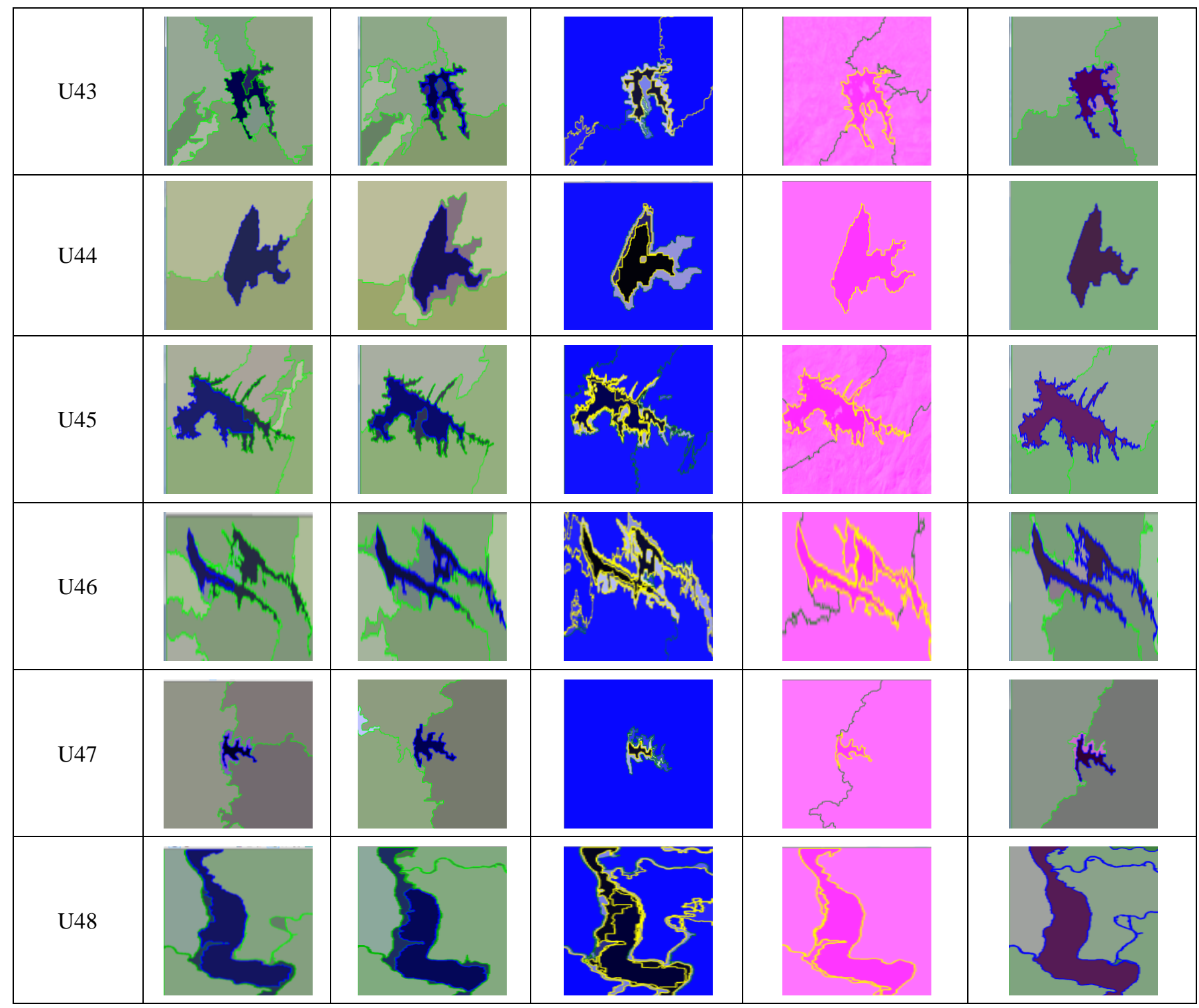

Figure 4 Resultant Images of Region based Segmentation using TCR

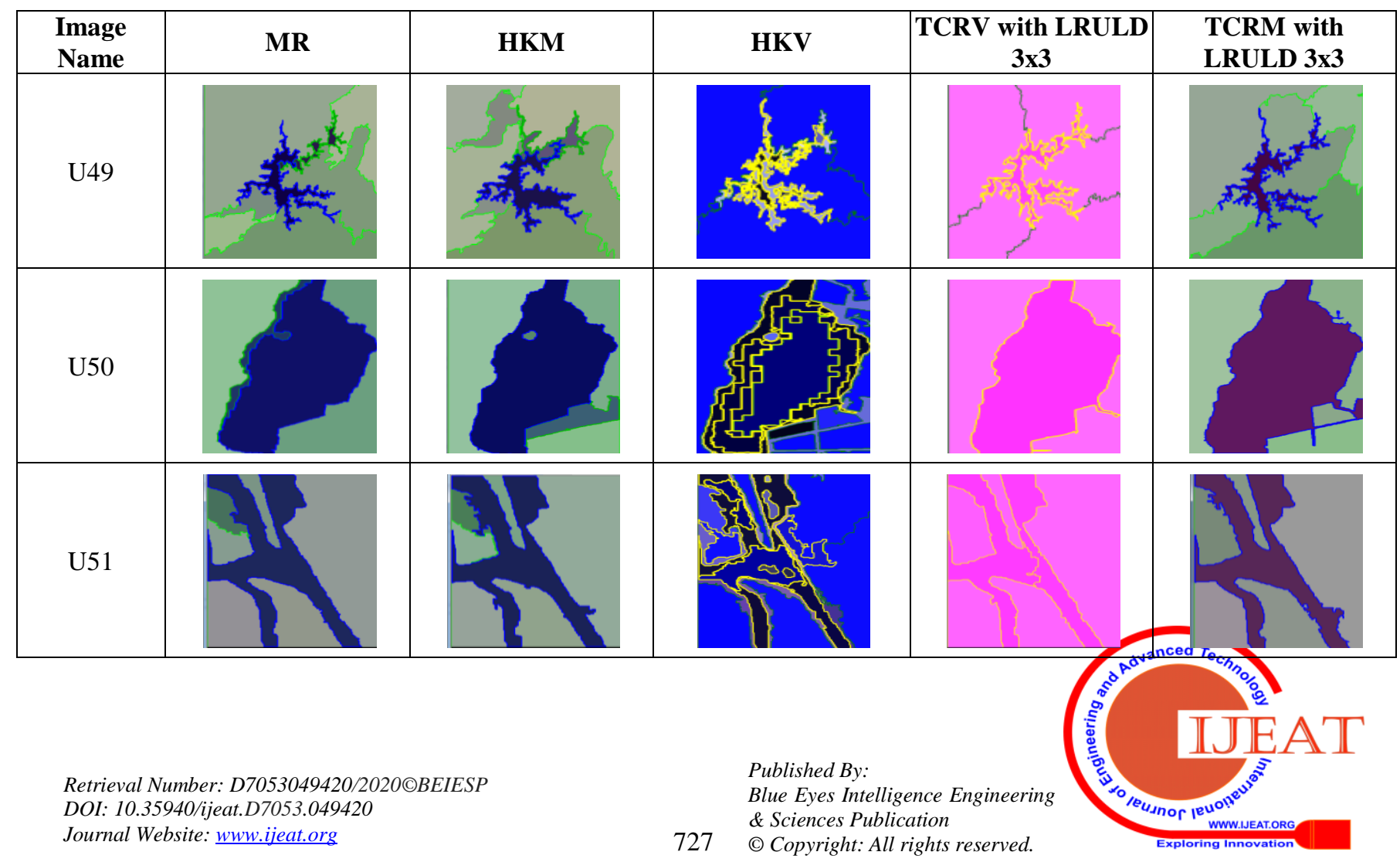




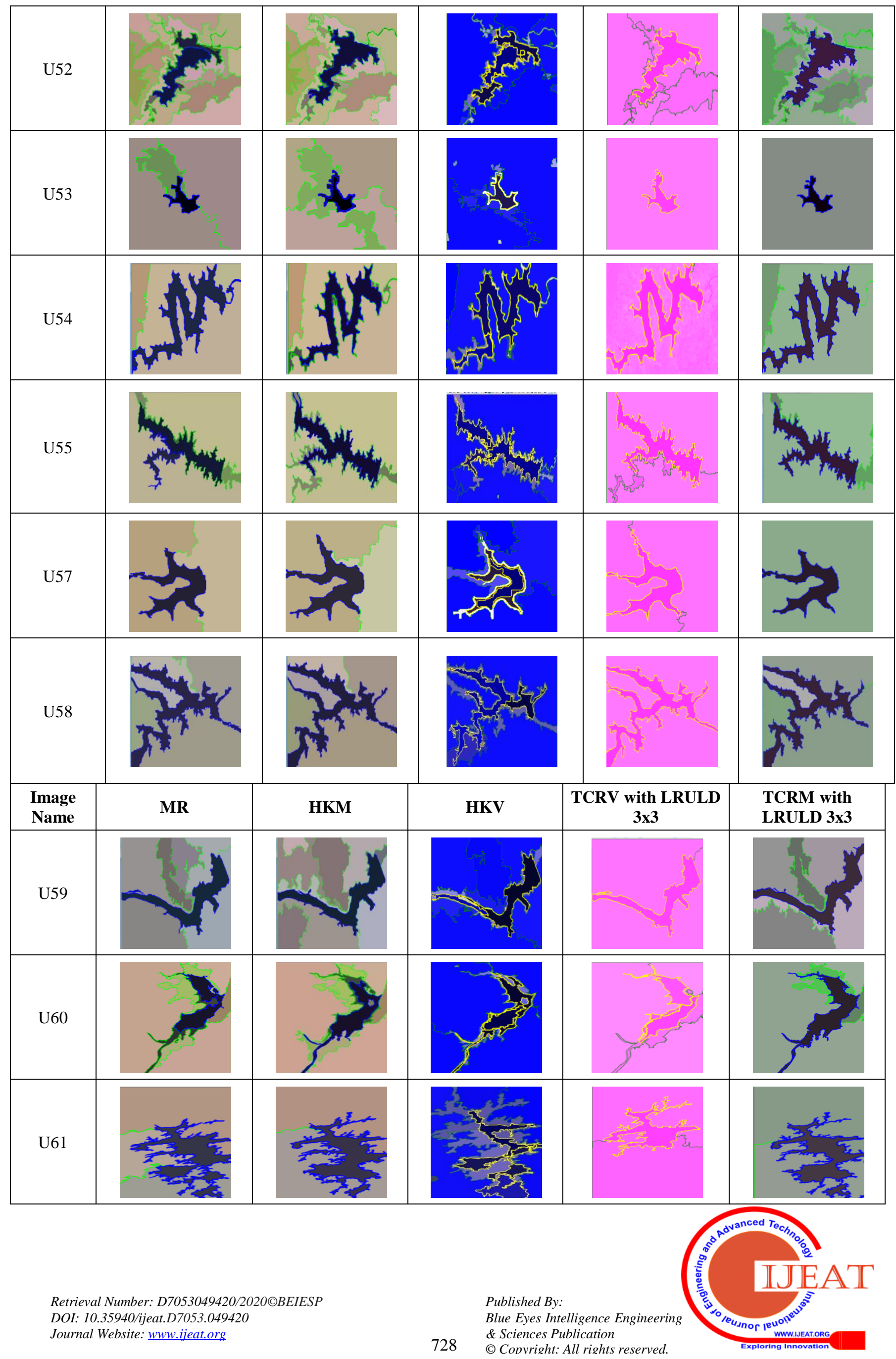




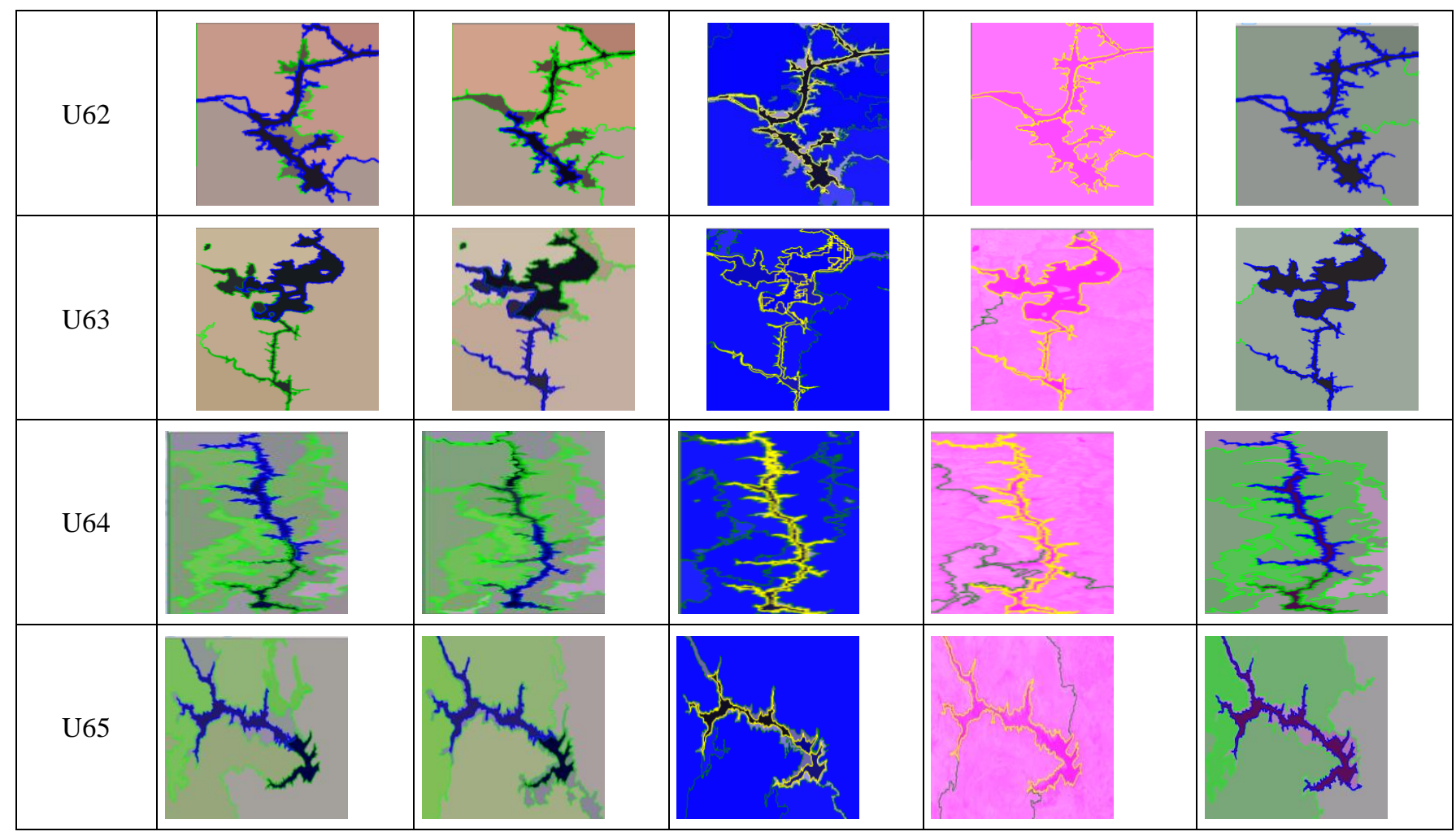

Table 2 Performance Evaluation of Region based Segmentation using TCRM5

\begin{tabular}{|c|c|c|c|c|c|c|c|c|c|}
\hline \multirow{3}{*}{$\begin{array}{l}\text { Image } \\
\text { Name }\end{array}$} & \multirow{3}{*}{$\begin{array}{c}\text { Image } \\
\text { Dimension }\end{array}$} & \multirow{3}{*}{ Threshold } & \multirow{3}{*}{$\begin{array}{l}\text { Water } \\
\text { Pixels }\end{array}$} & \multicolumn{6}{|c|}{ Percentage of Water Region using } \\
\hline & & & & \multirow{2}{*}{ MUL } & \multicolumn{2}{|c|}{ Existing } & \multicolumn{3}{|c|}{ TCRM 3x3 } \\
\hline & & & & & HKM & HKV & DIA & LR & LRD \\
\hline U41 & $770 \times 240$ & 140 & 31410 & 91.8465 & 104.8 & 75.8898 & 90.5985 & 92.2859 & 91.0124 \\
\hline U42 & $810 \times 515$ & 280 & 49228 & 97.5441 & 106.22 & 74.9411 & 96.8575 & 96.4228 & 95.5249 \\
\hline U43 & $220 \times 200$ & 60 & 2730 & 101.978 & 116.74 & 55.9341 & 102.308 & 81.538 & 103.443 \\
\hline U44 & $176 \times 126$ & 130 & 2782 & 96.9446 & 135.37 & 71.6751 & 88.0661 & 98.059 & 94.3206 \\
\hline U45 & $500 \times 345$ & 135 & 22602 & 101.115 & 105.1 & 76.2764 & 117.538 & 101.491 & 96.9206 \\
\hline U46 & $479 \times 153$ & 95 & 9735 & 98.2948 & 116.56 & 53.4977 & 123.297 & 99.2912 & 97.6168 \\
\hline U47 & $283 \times 236$ & 80 & 1210 & 73.3058 & 129.59 & 39.0909 & 111.322 & 93.5537 & 94.2975 \\
\hline U48 & $280 \times 496$ & 160 & 38905 & 102.356 & 127.33 & 130.223 & 105.046 & 104.28 & 105.275 \\
\hline U49 & $350 \times 340$ & 115 & 8574 & 103.989 & 146.59 & 53.8022 & 102.344 & 105.563 & 99.9883 \\
\hline U50 & $325 \times 528$ & 255 & 89442 & 84.136 & 113.59 & 70.91416 & 85.767 & 80.694 & 82.615 \\
\hline U51 & $198 \times 276$ & 111 & 17161 & 94.773 & 109.67 & 83.9928 & 91.2534 & 108.921 & 95.2334 \\
\hline U52 & $480 \times 430$ & 125 & 25564 & 107.53 & 104.98 & 80.68018 & 111.919 & 82.461 & 107.405 \\
\hline U53 & $200 \times 200$ & 95 & 1526 & 88.1389 & 110.03 & 67.3657 & 99.0826 & 87.3526 & 81.659 \\
\hline U54 & $520 \times 350$ & 245 & 38481 & 103.849 & 108.8 & 110.961 & 95.7641 & 98.5395 & 101.097 \\
\hline U55 & $655 \times 475$ & 225 & 52955 & 90.9848 & 108.34 & 78.461 & 89.4042 & 92.2859 & 88.6715 \\
\hline U56 & $625 \times 510$ & 225 & 62056 & 81.25 & 104.26 & 87.7369 & 98.3015 & 93.636 & 94.0876 \\
\hline U57 & 170x190 & 135 & 4111 & 99.8541 & 115.37 & 76.2102 & 98.6865 & 95.0377 & 98.7351 \\
\hline U58 & $740 \times 510$ & 355 & 77388 & 104.935 & 99.67 & 66.0025 & 98.225 & 104.021 & 82.977 \\
\hline U59 & $810 \times 500$ & 340 & 59999 & 110.294 & 101.54 & 78.3663 & 102.472 & 96.6849 & 97.405 \\
\hline U60 & 740x1050 & 340 & 99918 & 100.136 & 124.09 & 76.865 & 112.199 & 97.0936 & 95.116 \\
\hline U61 & $432 \times 745$ & 400 & 65842 & 100.808 & 103.37 & 62.1184 & 105.411 & 98.6452 & 97.0687 \\
\hline U62 & $576 \times 601$ & 255 & 42992 & 99.758 & 114.16 & 63.9584 & 99.7558 & 104.161 & 102.533 \\
\hline U63 & $1004 \times 1356$ & 470 & 190042 & 98.9266 & 104.36 & 67.4467 & 98.2946 & 98.5551 & 98.5551 \\
\hline U64 & $555 \times 1260$ & 220 & 56053 & 88.1327 & 108.96 & 77.391 & 117.014 & 99.2781 & 81.829 \\
\hline U65 & $600 \times 425$ & 205 & 18290 & 93.7132 & 92.76 & 64.6513 & 84.803 & 92.6987 & 86.1864 \\
\hline \multicolumn{4}{|c|}{ Average \% } & 96.58372 & 112.49 & 73.77807 & 101.0292 & 96.102 & 94.78292 \\
\hline
\end{tabular}

Retrieval Number: D7053049420/2020@BEIESP DOI: 10.35940/ijeat.D7053.049420

Journal Website: www.ijeat.org
Published By:

Blue Eyes Intelligence Engineering

\& Sciences Publication

729 (C) Copyright: All rights reserved.

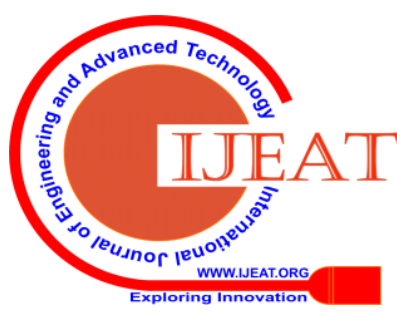


Table 3 Performance Evaluation of Region based Segmentation Using TCRM

\begin{tabular}{|c|c|c|c|c|c|c|c|c|c|}
\hline \multirow{3}{*}{$\begin{array}{l}\text { Image } \\
\text { Name }\end{array}$} & \multirow{3}{*}{$\begin{array}{c}\text { Image } \\
\text { Dimension }\end{array}$} & \multirow{3}{*}{ Threshold } & \multirow{3}{*}{$\begin{array}{l}\text { Water } \\
\text { Pixels }\end{array}$} & \multicolumn{6}{|c|}{ Percentage of Water region using } \\
\hline & & & & \multicolumn{4}{|c|}{ TCRM 3x3 } & \multirow{2}{*}{$\begin{array}{c}\text { TCRV 3x3 } \\
\text { LRULD }\end{array}$} & \multirow{2}{*}{$\begin{array}{c}\text { TCRM 5x5 } \\
\text { LRULD }\end{array}$} \\
\hline & & & & UL & ULD & LRUL & LRULD & & \\
\hline U41 & $770 \times 240$ & 140 & 31410 & 82.3114 & 91.9675 & 93.6581 & 98.7743 & 91.6301 & 91.4581 \\
\hline U42 & $810 x 515$ & 280 & 49228 & 98.0844 & 95.2385 & 98.0296 & 99.7806 & 105.639 & 93.8917 \\
\hline U43 & $220 \times 200$ & 60 & 2730 & 101.099 & 119.451 & 106.337 & 99.5971 & 90.421 & 111.136 \\
\hline U44 & $176 \times 126$ & 130 & 2782 & 95.6866 & 96.2257 & 95.2552 & 90.0072 & 101.186 & 98.8857 \\
\hline U45 & $500 \times 345$ & 135 & 22602 & 97.3896 & 78.065 & 100.168 & 99.7965 & 102.571 & 104.115 \\
\hline U46 & $479 \times 153$ & 95 & 9735 & 94.9563 & 96.0041 & 95.6959 & 99.6405 & 107.673 & 116.014 \\
\hline U47 & $283 x 236$ & 80 & 1210 & 91.5702 & 80.0826 & 84.3802 & 99.3388 & 69.0083 & 81.2397 \\
\hline U48 & $280 \times 496$ & 160 & 38905 & 99.691 & 129.384 & 99.71 & 99.8458 & 101.223 & 105.223 \\
\hline U49 & $350 \times 340$ & 115 & 8574 & 90.8444 & 101.201 & 100.023 & 106.158 & 107.756 & 98.6704 \\
\hline U50 & $325 \times 528$ & 255 & 89442 & 81.75 & 83.225 & 86.761 & 98.2469 & 95.6508 & 90.02 \\
\hline U51 & $198 \times 276$ & 111 & 17161 & 95.9676 & 96.0783 & 94.8022 & 97.3953 & 92.0343 & 101.573 \\
\hline U52 & $480 \times 430$ & 125 & 25564 & 105.328 & 105.422 & 103.802 & 95.9905 & 89.2701 & 106.76 \\
\hline U53 & $200 \times 200$ & 95 & 1526 & 92.6606 & 95.675 & 99.6723 & 98.3617 & 101.376 & 112.975 \\
\hline U54 & $520 \times 350$ & 245 & 38481 & 96.0162 & 96.1799 & 96.8894 & 96.8946 & 95.8395 & 93.8385 \\
\hline U55 & $\mathrm{x} 475$ & 225 & $52 !$ & 89.2135 & 86.0466 & 87.191 & 87.3326 & 86.8209 & 91.2756 \\
\hline U56 & $625 \times 510$ & 225 & 62056 & 97.2718 & 97.5957 & 98.9252 & 99.907 & 96.79 & 93.5349 \\
\hline U57 & 170x190 & 135 & 4111 & 105.108 & 94.9404 & 91.1457 & 97.9081 & 100.268 & 98.4919 \\
\hline U58 & $740 \times 510$ & 355 & 77388 & 103.032 & 94.3919 & 98.2943 & 97.855 & 96.7747 & 98.943 \\
\hline U59 & $810 \times 500$ & 340 & 59999 & 104.44 & 97.9916 & 99.0183 & 96.9766 & 86.6231 & 106.557 \\
\hline U60 & 740x1050 & 340 & 99918 & 97.9123 & 97.7241 & 97.7021 & 98.0904 & 83.2573 & 104.691 \\
\hline U61 & $432 \times 745$ & 400 & 65842 & 97.1568 & 99.4882 & 105.05 & 99.0462 & 70.7101 & 92.9437 \\
\hline U62 & $576 \times 601$ & 255 & 42992 & 82.068 & 96.1132 & 104.752 & 105.147 & 92.378 & 123.342 \\
\hline U63 & $1004 \times 1356$ & 470 & 190042 & 98.2783 & 97.3195 & 99.3359 & 99.1328 & 100.491 & 101.421 \\
\hline U64 & $555 \times 1260$ & 22 & 56053 & 94.1716 & 79.445 & 90.8212 & 98.319 & 94.0342 & 105.79 \\
\hline U65 & $600 \times 425$ & 205 & 18290 & 91.9557 & 86.1864 & 85.6228 & 114.562 & 119.65 & 85.53 \\
\hline & Av & $\%$ & & 98.39853 & 100.4577 & 98.5617 & 98.96418 & 97.24302 & 100.3328 \\
\hline
\end{tabular}

\section{REFERENCES}

1. Acharya, T. D., Subedi, A., Yang, I. T., \& Lee, D. H., 2017. Combining Water Indices for Water and Background Threshold in Landsat Image. In Multidisciplinary Digital Publishing Institute Proceedings, 2(3), 143.

2. Akay, HG \& Aksoy, S 2008, 'Automatic detection of geospatial objects using multiple hierarchical segmentations', IEEE Transactions on Geoscience and Remote Sensing, vol. 46, no.7, pp. 2097-2111.

3. Arcidiacono, C, Porto, SMC \&Cascone, G 2012, 'Accuracy of crop-shelter thematic maps: a case study of maps obtained by spectral and textural classification of high-resolution satellite images', Journal of Food Agricculture Environment, vol. 10, pp.1071-1074.

4. Blaschke, T \&Strobel, J 2001, 'What's wrong with pixels? some recent developments interfacing remote sensing and GIS', Proceeding of GIS Zeitschriftfür Geo informations system, Hüthig GmbH \& Co. KG Heidelberg, pp. 12-17.

5. Breckle, SW \& Wucherer, W 2006, '16 vegetation of the pamir (tajikistan): land use and desertification problems in land use change and mountain biodiversity', Taylor \& Francis, Boca Raton, FL, USA, pp. 225-237.

6. Coggins, JM \& Jain, AK 1985, 'A spatial filtering approach to texture analysis', Pattern Recognition Letters, pp. 195-203.

7. Csathó, B, Schenk, T, Lee, DC \& Filin, S 1999, 'Inclusion of multispectral data into object recognition', International Archives of the Photogrammetry, Remote Sensing Spatial Information Science, vol. 32, pp. 53-61.

8. Fisher, A, Flood, N, \& Danaher, T, 2016, 'Comparing Landsat water index methods for automated water classification in eastern Australia', Remote Sensing of Environment, vol. 175, pp. 167-182.

9. Gagalowicz, A 1988, 'Blind texture segmentation', Proceding of the 9th International Conference on Pattern Recognition, pp. 46-50.

10. Haralick, RM, Shanmugam, K \&Dinstein, I 1973, 'Texture for image classification', IEEE Transaction Systems Man Cybernet, vol.3, no.3, pp. 610-621.

11. Hauta - Kasari, M, Parkkinen, J, Jaaskelainen, T \& Lenz, R 1996 'Generalized cooccurrence matrix for multispectral texture analysis', Proceding of the 13th International Conference on Pattern Recognition, pp. 785-789.
12. Isikdogan, F., Bovik, A.C. and Passalacqua, P., 2017. Surface Water Mapping by Deep Learning. Ieee Journal of Selected Topics in Applied Earth Observations and Remote Sensing,10(11),pp.17-28.

13. Jain, AK 1989, 'Fundamentals of digital image processing, Prentice Hall, Englewood Cliffs, New Jersey.

14. Jupp, DLB, Mayo, KK, Kuchler, DA, Heggen, SJ, Kendall, SW B.M. Radke, BM \&Ayling, T 1985, 'Landsat based interpretation of the cairns section of the great barrier reef marine park', Australia Commonwealth Scientific \& Industrial Research Organization Division of Water \& Land Resources Natural Resources Series (4), pp. 1-51

15. Lin, HC, Wang, LL \&Yang, SN 1997, 'Extracting periodicity of a regular texture based on autocorrelation functions', Pattern Recognition Letters, vol. 18, no. 5, pp. 433-443.

16. Menaka, E \& Suresh Kumar, S, "Analysis Deforestation Using Threshold Based Clustering Algorithm", International Journal of Applied Engineering Research 9 (23), 21031-21054, 2014.

17. Menaka, E \& Suresh Kumar, S, "Improving segmentation accuracy for detecting deforestation using texture feature derived from Landsat 8 OLI multispectral imagery", European Journal of Remote Sensing, Vol.48, pp.169-181, 2015.

18. Myint, SW, Gober, P, Brazel, A, Grossman-Clarke, S \& Weng, Q 2011 , 'Per-pixel vs. object-based classification of urban land cover extraction using high spatial resolution imagery', Remote Sensing Environment, vol. 115, pp. 1145-1161.

19. Pesaresi, M \& Gerhardinger, A 2011, 'Improved textural built-up presence index for automatic recognition of human settlements in arid regions with scattered vegetation', IEEE Journal Selecting Topics in Applied Earth Observing Remote Sensing, vol. 4, pp. 16-26.

20. Wei Jiang, Guojin He, Tengfei Long, Yuan Ni 2018, 'Detecting water bodies in Landsat 8 OLI image using deep learning', The International Archives of the Photogrammetry, Remote Sensing and Spatial Information Sciences, vol. 43 (3), pp. 669-672.

21. Wentz, EA, Stefanov, WL, Gries, C \& Hope, D 2006, 'Land use and land cover mapping from diverse data sources for an arid urban environments', Computing Environment Urban System vol. 30, pp 320-346.

Published By:

Blue Eyes Intelligence Engineering 
22. Wilson, PA 1997, 'Rule-based classification of water in landsat MSS images using the variance filter, Photogrammetric Engineering \& Remote Sensing, vol. 63, no. 5, pp. 485 - 491.

23. Wood, EM, Pidgeon, AM, Radeloff, VC, Keuler, NS 2012, 'Image texture as a remotely sensed measure of vegetation structure', Remote Sensing Environment, vol. 121, pp. 516-526.

\section{AUTHORS PROFILE}

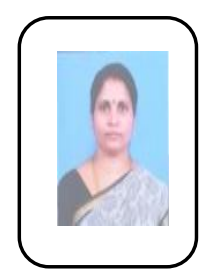

Dr. M. Umaselvi - has received B.E CSE and M.E CSE in 2002 and 2006respectively. She has pursued her Ph.D. (Image Processing, 2019) from Anna University, Chennai. Presently she is working as Associate Professor in Dept. of CSE, P.A College of Engineering and Technology, Coimbatore, Tamil Nadu, India. She has academic experience of 10 years and she has presented papers in five International Journals, four International conferences and six National conferences in various fields. She is a Member of Institute of Research Engineers and Doctors (IRED), International Association of Engineers (IAENG). Her areas of interest are Satellite image processing and analysis, pattern recognition and Wireless Sensor Networks.

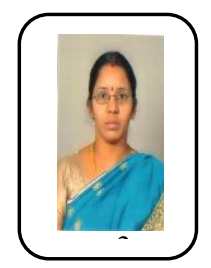

Dr. E. Menaka - has received B.E CSE and M.E CSE in 2002 and 2006 respectively. She has pursued her Ph.D. (Image Processing, 2017) from Anna University, Chennai, Tamil Nadu. Presently she is working as Associate Professor in Dept. of CSE, Vivekanandha College of Engineering for Women, Namakkal, Tamil Nadu, and India. She has academic experience of 15 years and she has presented papers in 25 International Journals, 18 International Conferences and 13 National Conferences in various fields. She is a Member of IET, IAENG, SAGE, CSE and ISSE. Her areas of interest are Satellite image processing \& analysis and Wireless Sensor Networks.

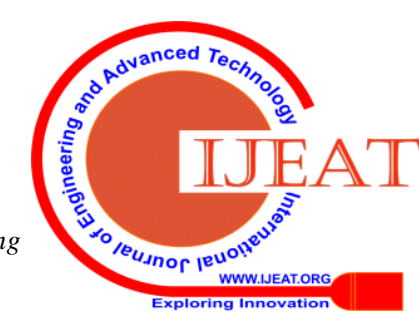

